\title{
PEMERIKSAAN BADAN KETON PADA URINE PENDERITA DIABETES MELLITUS TIPE II (NIDDM) YANG DI RAWAT INAP DI RSUP H. ADAM MALIK MEDAN
}

\author{
Ice Ratnalela Siregar \\ Jurusan Analis Kesehatan Politeknik Kesehatan Kemenkes Medan
}

\begin{abstract}
Abstrak
Diabetes mellitus merupakan gangguan metabolisme dari distribusi gula oleh tubuh. Penderita diabetes tidak bisa memproduksi insulin dalam jumlah yang cukup, atau tidak mampu menggunakan insulin secara efektif, sehingga terjadi kelebihan gula dalam darah. Kelebihan gula yang kronis dalam darah ( hiperglikemia) ini menjadi racun dalam tubuh. Sebagian glukosa yang bertahan di dalam darah itu melimpah ke system urin untuk di buang melalaui urin. Pada tubuh yang sehat pancreas melepas hormone insulin yang bertugas mengangkut gula melalui darah ke otot-otot dan jaringan lain untuk memasok energi. Pencetus utama Diabetes mellitus tipe II dapat di sebut karena factor obesitas atau kegemukan dan factor lain adalah adalah pola makan yang salah, proses penuaan, dan stress yang mengakibatkan terjadinya resistensi insulin. Kelompok diabetes mellitus tipe II dapat mengalai ketoasiosis, tetapi hal ini jarang terjadi.Ketoasidosis terjadi karena tidak adanya insulin yang di hasilkan. Akibat dari defisiensi insulin yang lain adalah pemecahan lemak menjadi asam-asam lemak bebas dan gliserol. Asam-asam lemak bebas akan di ubah menjadi badan keton oleh hati. Badan ketone bersifat asam dan bila bertumpuk dalam sirkulasi darah badan keton akan menimbulkan ketoasidosis diabetic. Ketoasidosis diabetic adalah komplikasi akut diabetes mellitus yang serius dan harus segera ditangani. Ketoasidosis diabetic memerlukan penanganan yang cepat dan tepat mengingat angka kematian yang tinggi. Pemeriksaan badan ketone pada urin penderita diabetes mellitus di lakukan di laboratorium. Telah di lakukan pemeriksaan badan ketone pada urine penderita diabetes mellitus tipe II yang di rawat inap di RSUP H Adam Malik Medan dengan sampel urine segar yang di laksanakan di laboratorium politeknik Kesehatan Jurusan Analis Kesehatan Medan pada tanggal 12-16 juli 2010 terhadap 20 orang pasien baik pria atau wanita. Dari hasil penelitiandi perolehkesimpulan bahwa pada saat melakukan penelitian tidak di temukan badan ketone pada urin penderita diabetes mellitus.
\end{abstract}

Kata Kunci : Diabetes Mellitus, Keton

\section{PENDAHULUAN}

\section{Latar Belakang}

Diera globalisasi saat ini banyak jenis penyakit yang diderita oleh masyarakat mulai dari kalangan bawah sampai kalangan atas tanpa memandang ras, budaya, agama, usia, dan jenis kelamin. Rumah Sakit Umum Pusat Haji Adam Malik Medan adalah Rumah sakit rujukan yang banyak di kunjungi masyarakat untuk mendapatkan pengobatan dari berbagai penyakit. Rumah sakit ini berlokasi di jalan Bunga Lau Medan, yang terdiri dari dua ruangan yaitu Rindu A dan Rindu B. Di rumah sakit ini banyak pasien yang dirawat dengan berbagai penyakit, salah satunya adalah penyakit Diabetes Millitus yang di rawat di bagian penyakit dalam sub bagian endokrin.

Menurut WHO (organisasi kesehatan sedunia) tahun 2003 terdapat lebih dari 200 juta orang dengan diabetes di dunia. Angka ini akan bertambah menjadi 333 juta orang di tahun 2025. Negara berkembang seperti Indonesia merupakan daerah yang paling banyak terkena pada abat ke 2 ini. Indonesia merupakan Negara dengan jumlah diabetisi ke-4 terbanyak di dunia menurut versi WHO. Pada tahun 2000 di Indonesia terdapat 8,4 juta diabetisi (yang menderita penyakit diabetes) dan diperkirakan akan menjadi 21,3 juta pada tahun 2030 (Soegondo, 2008).

Penelitian epidemiologi di Jakarta (urban), mendapat prevalensi DM 1,7\% (1982), 5,7\% (1993), dan menjadi 12,8\% pada tahun 2001. Tahun 2003 diperkirakan prevalensi DM di daerah perkotaan menjadi 14,7\% (8,2 juta diabetisi ) dan di daerah pedesaan $7,2 \%$ (5,5 juta diabetisi ). Tahun 2030 dengan prevalensi DM yang sama akan terdapat 12 juta diabetisi di daerah urban dan 8,1 di daerah rural. Sepuluh Negara di dunia yang paling banyak terdapat diabetisi saat ini menurut WHO, Brazil, dan Banglades (Soegondo, 2008).

Diabetes Millitus adalah suatu penyakit dimana tubuh penderita tidak bisa secara otomatis mengendalikan tingkat gula (glukosa) dalam darahnya. Pada tubuh yang sehat, pankreas melepaskan hormon insulin yang bertugas mengangkut gula melalui darah ke otot-otot dan jaringan lain untuk memasok energi (Mangoenprasodjo, 2005). 
Kelompok Diabetes Millitus tipe II dapat juga memgalami ketoasidosis, tetapi kasus ini jarangterjadi karena masih memiliki sedikit insulin, walaupun insulin tersebut tidak dapat berfungsi secara optimal akibat terjadinya resistensi insulin. Orang dengan diabetes mellitus tipe II dapat mengalami ketoasidosis apabila mengalami infeksi berat atau trauma sehingga tubuhnya dalam kondisi stress fisik yang berat (Soegondo,2008).

Ketoasidosis diabetik adalah komplikasi akut diabetes mellitus yang serius dan harus segara ditanggani . Ketoasidosis diabetik memerlukan pengelolaan yang cepat dan tepat, mengingat angka kematian yang tinggi. Dengan demikian, sangat penting bagi penderita diabetes mellitus untuk mengontrol gula darah dan membuat menu makanan untuk menekan peningkatan kadar gula darahnya (Utama, $\mathrm{H}$, 2003). Dari latar belakang di atas, penulis tertarik untuk mengetahui sejauh mana gambaran badan keton pada penderita diabetes mellitus tipe II yang dirawat inap di rumah sakit umum Haji Adam Malik Medan bagian Poliklinik Endokrin.

\section{Perumusan Masalah}

Bagaimanakah gambaran badan keton pada penderita Diabetes Mellitus yang dirawat inap di RSU Pusat Haji Adam Malik Medan?

\section{Tujuan Penelitian}

Untuk mengetahui badan keton pada urin penderita Diabetes Mellitus yang dirawat inap di RSU Pusat Haji Adam Malik Medan.

\section{Manfaat Penelitian}

1. Untuk mengembangkan pengetahuan ilmiah, pengalaman peneliti di bidang Kimia Klinik.

2. Sebagai informasi pada penderita Diabetes Mellitus tentang badan keton yang terdapat pada urin.

\section{METODE PENELITIAN}

\section{Tempat dan Waktu}

Penelitian ini dilakukan di laboratorium Politehnik Kesehatan Negeri Jurusan Analis Kesehatan Medan pada bulan Juli 2010, dengan menggunakan metode penelitian yang akan di pakai adalah bersifat deskriptif

\section{Populasi dan Sampel}

Populasi penelitian adalah dari jumlah total penderita Diabetes Millitus yang telah didiagnosa Dokter di RSUP Haji Adam Malik diambil sebanyak 20 sampel.

\section{Bahan, Alat dan Reagensia Bahan Penelitian}

Bahan yang digunakan untuk penelitian adalah Urin segar. Urin segar adalah urin yang kurang dari 2 jam setelah dikemihkan. Urin ditampung dalam wadah yang memiliki tutup yang rapat.

\section{Alat Penelitan}

- Tabung reaksi

- Wadah tempat penampungan urin

- Rak tabung

- Pipet tetes

\section{Reagensia}

Reagensia yang digunakan pada penelitian adalah ferrichlorida $10 \%$.

\section{Metode Pemeriksaan} Gerhardt.

Metode pemeriksaan yang digunakan adalah secara

\section{Prinsip Kerja}

Asam acetoasetat yang ada di dalam urin bereaksi dengan ferryclorida dan membentuk warna merah coklat (seperti anggur).

\section{Perosedur Kerja}

Langkah-langkah kerja pemeriksaan badan ketone menggunakan metode Gerhardt adalah:

- Ambil $5 \mathrm{ml}$ urine, lalu masukkan ke dalam tabung reaksi.

- Lalu tetesi dengan larutan Ferrichlorida $10 \%$ ke dalam tabung sambil mengocok isinya.

- Jika terbentuk presipitat putih ferrifostat berhenti, lalu saringlah cairan itu.

- Lalu pada filtrate diberikan beberapa tetes larutan Ferrichlorida lagi.

- Perhatikan apa yang terjadi, adanya warna merah coklat yang menandakan tes ini positif.

\section{Interpresrasi Hasil}

- Positif bila terjadi warna merah anggur.

- Negatif bila tidak terjadi perubahan warna.

\section{HASIL DAN BAHASAN}

\section{Hasil Penelitian}

Dari penelitian yang dilakukan terhadap 20 sampel pasien dari total seluruh penderita Diabetes Mellitus Tipe II yang di rawat inap di RSUP H Adam Malik Medan, pada bulan juli 2010 maka di peroleh hasil sebagai berikut: 
Tabel Hasil Pemeriksaan Badan Keton Pada Urine Penderita Diabetes Mellitus Tipe II Yang Di Rawat Inap di RSUP H Adam Malik Medan

\begin{tabular}{|c|c|c|c|c|c|c|}
\hline No & Nama Pasien & Umur (Tahun) & Jenis Kelamin & KGD Adrandom & Hasil Keton Urine & Keterangan \\
\hline 1 & SR & 40 & Lk & $350 \mathrm{mg} / \mathrm{dl}$ & Negatif & Normal \\
\hline 2 & FS & 55 & $\operatorname{Pr}$ & $400 \mathrm{mg} / \mathrm{dl}$ & Negatif & Normal \\
\hline 3 & $\mathrm{MN}$ & 52 & Lk & $280 \mathrm{mg} / \mathrm{dl}$ & Negatif & Normal \\
\hline 4 & ED & 50 & $\mathrm{Lk}$ & $300 \mathrm{mg} / \mathrm{dl}$ & Negatif & Normal \\
\hline 5 & SP & 60 & $\operatorname{Pr}$ & $350 \mathrm{mg} / \mathrm{dl}$ & Negatif & Normal \\
\hline 6 & $\mathrm{RD}$ & 57 & Lk & $380 \mathrm{mg} / \mathrm{dl}$ & Negatif & Normal \\
\hline 7 & TS & 53 & Lk & $420 \mathrm{mg} / \mathrm{dl}$ & Negatif & Normal \\
\hline 8 & MS & 55 & $\operatorname{Pr}$ & $360 \mathrm{mg} / \mathrm{dl}$ & Negatif & Normal \\
\hline 9 & $\mathrm{MH}$ & 52 & $\operatorname{Pr}$ & $420 \mathrm{mg} / \mathrm{dl}$ & Negatif & Normal \\
\hline 10 & SN & 62 & $\operatorname{Pr}$ & $310 \mathrm{mg} / \mathrm{dl}$ & Negatif & Normal \\
\hline 11 & NR & 55 & $\operatorname{Pr}$ & $345 \mathrm{mg} / \mathrm{dl}$ & Negatif & Normal \\
\hline 12 & AS & 56 & Lk & $410 \mathrm{mg} / \mathrm{dl}$ & Negatif & Normal \\
\hline 13 & NS & 61 & $\operatorname{Pr}$ & $320 \mathrm{mg} / \mathrm{dl}$ & Negatif & Normal \\
\hline 14 & HT & 58 & $\operatorname{Pr}$ & $250 \mathrm{mg} / \mathrm{dl}$ & Negatif & Normal \\
\hline 15 & JK & 60 & Lk & $280 \mathrm{mg} / \mathrm{dl}$ & Negatif & Normal \\
\hline 16 & $\mathrm{AG}$ & 45 & Lk & $300 \mathrm{mg} / \mathrm{dl}$ & Negatif & Normal \\
\hline 17 & HL & 50 & Lk & $250 \mathrm{mg} / \mathrm{dl}$ & Negatif & Normal \\
\hline 18 & $\mathrm{TN}$ & 67 & PR & $280 \mathrm{mg} / \mathrm{dl}$ & Negatif & Normal \\
\hline 19 & $\mathrm{BB}$ & 55 & Lk & $400 \mathrm{mg} / \mathrm{dl}$ & Negatif & Normal \\
\hline 20 & DP & 57 & $\operatorname{Pr}$ & $250 \mathrm{mg} / \mathrm{dl}$ & Negatif & Normal \\
\hline
\end{tabular}

\section{Pembahasan}

Setelah di lakukan penelitian tentang pemeriksaan badan keton pada urin dengan menggunakan metode Gerhard menggumakan reagen ferri clorida 10\% pada pasien yang sudah di rawat inap di RSUP H Adam Malik Medan terhadap 20 pasien yang sudah di diagnosa menderita diabetes mellitus tipe II, dari 20 penderita 100\% di jumpai pada usia 40 tahun keatas dimana laki-laki 10 orang (50\%) dan perempuan 10 orang (50\%) pada umumnya badan keton pada urinnya adalah tidak ada atau hasilna dalah negative.

Tidak ditemukannya badan keton pada urin penderita diabetes mellitus dapat di sebabkan karena penderita diabetes mellitus selalu mengontrol gula darah nya dan sedang mengkonsumsi obat. Biasanya badan keton di temukan pada urin penderita diabetes mellitus yang telah mengalami koma, yang di sebut Koma Diabetik. Koma pada penderita diabetes mellitus ini di akibatkan kadar glukosa darah terlalu tinggi, biasanya melebihi $600 \mathrm{mg} / \mathrm{dl}$ (Mangoenprasetio, setiono, 2005).

Walaupun tidak ditemukannya badan keton pada urine, pemeriksaan laboratorium tetaplah sangat di perlukan, karena pemeriksaan laboratorium ini sangat bermanfaat untuk memantau perkembangan kesehatan dari pasien dan untuk menentukan salah satu diagnosa penyakit.

\section{KESIMPULAN DAN SARAN}

\section{Kesimpulan}

Berdasarkan hasil penelitian dari 20 sampel, lakilaki sebanyak 10 orang (50\%) dan perempuan 10 orang (50\%) yang di rawat inap di RSUP H Adam Malik Medan tidak di temukan badan keton pada urin penderita diabetes mellitus tipe II atau hasilnya Negatif.

\section{Saran}

1. Bagi penderita Diabetes Mellitus agar selalu melakukan pemeriksaan badan keton pada urin nya.

2. Penderita diabetes mellitus selalu melakukan pengontrolan kadar gula darahnya.

3. Penderita Diabetes Mellitus agar memperhatikan makanan yang di konsumsinya.

\section{DAFTAR PUSTAKA}

Soegondo Sidartawan, 2008, Hidup Sehat Mandiri Dengan Diabetes Militus, Kencing Manis Sakit Gula, Fakultas Kedokteran UI, Jakarta

Hutagalung, Halomoan, 2004, Karbohidrat, Medan

Murrayk, Robert, 2009, Biokimia Harper, Buku Kedokteran, Jakarta, Edisi 27

Baron, 1995, Capital Selecta Patologi Klinik, Buku Kedokteran, Jakarta, Edisi 4

Sustrani, Lanny, 2006, Diabetes, PT. Gramedia Pustaka Utama, Jakarta.

Mangoenprasodjo, Setiono, 2005, Hidup Sehat Dan Normal Dengan Diabetes Thinkfresh, Yogyakarta.

Price, Sylvia Anderson, 1995, Patofisiologi, Buku Kedokteran, Jakarta, Edisi 4

C. Smeltzer, Suzanne, 2004, Keperawatan Medical Bedah, Buku Kedokteran, Jakarta, Edisi 8.

R. A Nabyl, 2009, Diabetes Militus, Aulia Publishing, Yogyakarta

Shahap, Alwi, 2006, Diagnosa dan Peñatalaksanaan Diabetes Militus, Palembang

R. Gandasubrata, 2007, Penuntun Laboratorium Klinik, Dian Rakyat, Jakarta.

Tjokroprawiro, Askandar, 2007, Ilmu Penyakit Dalam, Airlangga University Press, Surabaya

Utama, H, 2003, Ilmu Penyakit Dalam, Gaya Baru, Jakarta, Edisi 1.

Robin, Stanle, 1995, Patologi, Penerbit Buku Kedokteran, Jakarta, Edisi 4. 